\title{
Incoherency between the clinical condition and the chest X-ray result in COVID-19 patients: a case series
}

\author{
Septian Adi Permana1 ${ }^{*}$, Dita Aditianingsih¹, Muhammad Husni Thamrin², Arifin², Purwoko
}

Author affiliations:

1. Anesthesiology \& Intensive Care Department, University Indonesia, Jakarta, Indonesia.

2. Intensive Care Department, Dr. Moewardi General Hospital, Surakarta, Indonesia.

*Correspondence: Septian Adi Permana; E-mail: septian.adi03@gmail.com

\section{Abstract}

Despite the routine dependence upon chest X-ray (CXR) to monitor COVID-10 patients' condition, we found that CXR and the clinical condition of some patients were incoherent, especially regarding the need of oxygen supplementation. In our patients, the incoherency was found in three patients, although, the PCR test result was still positive. In the first patient, we noted from the CXR that the pulmonary infiltrate was getting worse, but the oxygen demand was getting less and the $\mathrm{PaO}_{2} / \mathrm{FiO}_{2}$ was getting better on Day 4. For the second patient it happened on Day 4 and 5. In our third patient, it happened on the Day 6 and 11. All of the patients were cured and discharged home safely. Our finding indicates that we have to rely more on the clinical condition and subjective complaints of the patients, rather than CXR results to evaluate the therapy because there may be an incoherency between the two.

Key word: COVID-19; Timeline; Incoherency; Clinical condition

Citation: Permana SA, Aditianingsih D, Thamrin MH, Arifin, Purwoko. Incoherency between the clinical condition and chest X-ray result in COVID-19 patients: a case series. Anaesth. pain intensive care 2021;25(6):798-803 ; DOI: 10.35975/apic.v25i6.1710

Received: September 11, 2021, Reviewed: September 22, 2021, Accepted: September 24, 2021

\section{Introduction}

COVID-19 is an infectious viral disease that has spread worldwide. In Indonesia, the data from covid19.go.id shows that by 8 October 2020, COVID-19 positive cases were 320564 and the mortality due to this infection was 11,580; the number continues to increase. ${ }^{1,2}$ This infection can be diagnosed by chest X-ray (CXR), even though the sensitivity rate is not as high as real time polymerase chain reaction (RT-PCR) test (chest X-ray $69 \%$ vs. RT-PCR 91\%). ${ }^{3,4,5}$ Other than CXR, we can also diagnose the infection by CT scan thorax with a sensitivity of $98 \%$, which is greater than RT PCR (71\%). We found an incoherency in some of the patients who reported to our hospital. With treatment for few days the patients' oxygen demand was noted to be decreasing until the day of discharge, but the chest X-ray presented a worst picture, even though, the PCR test results were also found negative. It looks that the treating physicians cannot rely upon a single test only, to judge about the outcome of the disease, but must also consider the physical condition and the results of other laboratory tests of the patients. We present here three COVID-19 patients with a similar incoherency, in which, although the clinical and laboratory reports showed much improvement, the CXR result was getting worse. This indicates the incoherency between those two parameters. ${ }^{4-8}$

\section{Case Report 1}

A male patient, aged $30 \mathrm{y}$, was positive for COVID-19 with RT-PCR test. He had fever, dyspnea, cough, and tachycardia for a week. The patient was an active smoker but had no previous history of dyspnea or other illnesses. He lived in an endemic area for COVID-19 in Central Java.

Table 1 shows his clinical picture and laboratory data from Day 1 to Day 10 . He was managed by $15 \mathrm{~L} / \mathrm{min}$ of oxygen through a non-rebreathing mask on Day 1, and then shifted to $100 \%$ oxygen with Helmet CPAP, gradually decreasing to $60 \%$. 


\begin{tabular}{|c|c|c|c|c|c|c|c|}
\hline Day & 1 & 2 & 3 & 4 & 5 & 7 & 10 \\
\hline GCS & Fully alert & Fully alert & Fully alert & Fully alert & Fully alert & Fully alert & Fully alert \\
\hline $\mathrm{BP}(\mathrm{mmHg})$ & $130 / 80$ & $127 / 88$ & $118 / 80$ & $108 / 54$ & $103 / 160$ & $94 / 60$ & $117 / 76$ \\
\hline HR (bpm) & 120 & 78 & 74 & 78 & 89 & 70 & 86 \\
\hline $\mathrm{RR}(/ \mathrm{min})$ & 30 & 28 & 30 & 30 & 24 & 22 & 23 \\
\hline Temp $\left({ }^{\circ} \mathrm{C}\right)$ & 37,2 & 36,2 & 36,8 & 36,5 & 36,7 & 36,5 & 36,5 \\
\hline $\mathrm{SpO}_{2}(\%)$ & 85 & 98 & 98 & 98 & 93 & 97 & 97 \\
\hline Therapy & $\begin{array}{l}\text { NRM } 15 \\
\mathrm{~L} / \mathrm{min}\end{array}$ & $\begin{array}{l}\text { Helmet } \\
\text { CPAP } 100 \%\end{array}$ & $\begin{array}{l}\text { Helmet } \\
\text { CPAP 86\% }\end{array}$ & $\begin{array}{l}\text { Helmet } \\
\text { CPAP } \\
60 \%\end{array}$ & $\begin{array}{l}\text { NRM } 10 \\
\text { L/min }\end{array}$ & $\begin{array}{l}\mathrm{NRM} 8 \\
\mathrm{~L} / \mathrm{min}\end{array}$ & $\mathrm{NC} 4 \mathrm{~L} / \mathrm{min}$ \\
\hline
\end{tabular}

GCS: Glasgow Coma Scale; BP: blood pressure; HR: heart rate; RR: respiratory rate; Temp: temperature; NRM: non rebreathing mask; CPAP: continuous positive airway pressure; NC: nasal cannula
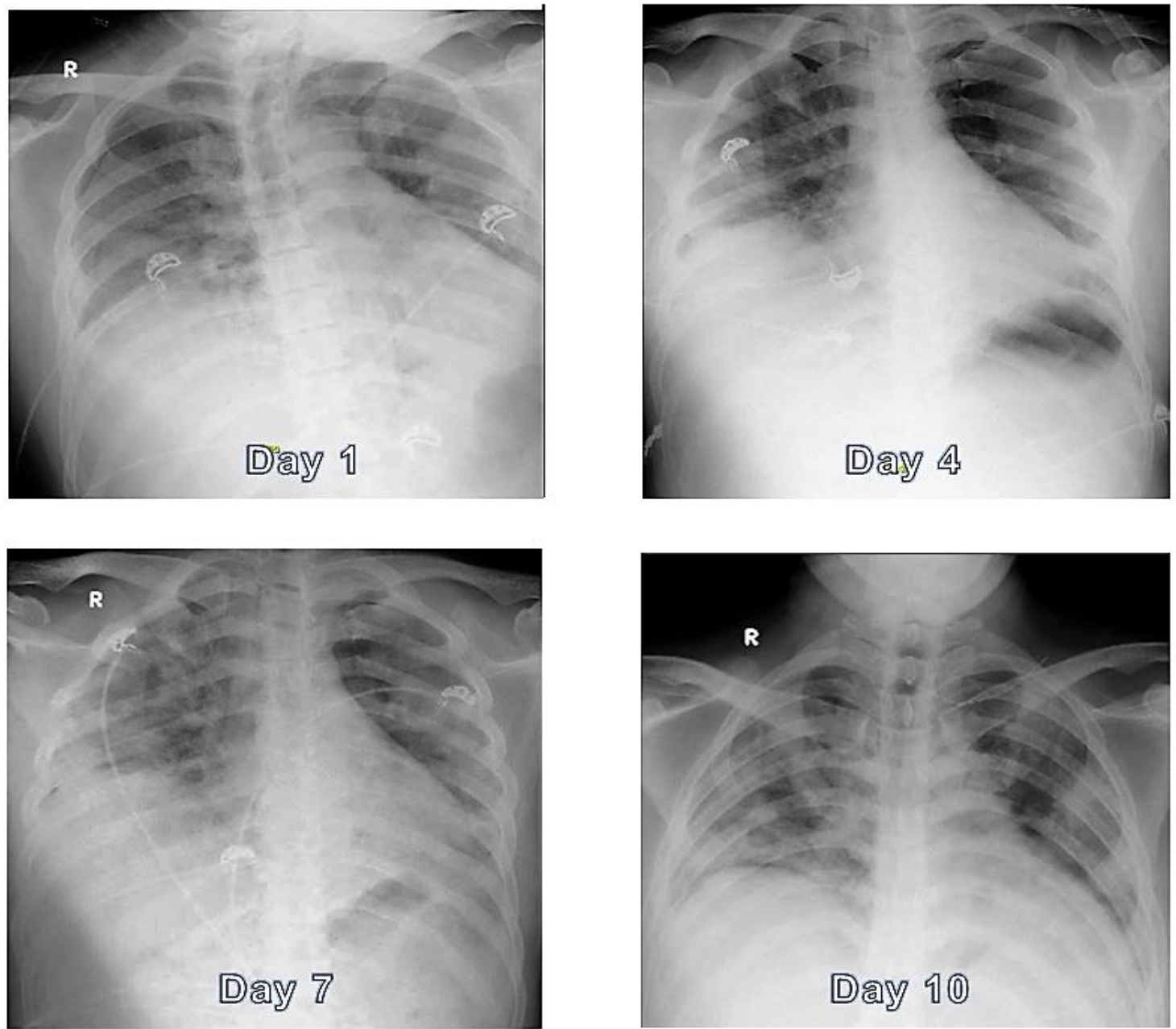

Figure 1: Chest $\mathrm{X}$-ray presentations show bilateral infiltrates with ground glass opacity Becoming coarser from 1st until 9th day; the infiltrates reduced on the day 10 
Table 2: Clinical presentations of the 2nd patient

\begin{tabular}{|c|c|c|c|c|c|c|}
\hline Day & 1 & 2 & 4 & 5 & 7 & 11 \\
\hline GCS & Fully alert & Fully alert & Fully alert & Fully alert & Fully alert & Fully alert \\
\hline $\mathrm{BP}(\mathrm{mmHg})$ & $115 / 92$ & $115 / 75$ & $131 / 74$ & $131 / 90$ & $128 / 90$ & $112 / 80$ \\
\hline HR (bpm) & 90 & 85 & 91 & 81 & 83 & 89 \\
\hline $\mathrm{RR}(/ \mathrm{min})$ & 20 & 22 & 19 & 20 & 20 & 19 \\
\hline Temp $\left({ }^{\circ} \mathrm{C}\right)$ & 37 & 36.5 & 36.5 & 36.5 & 36.5 & 36 \\
\hline $\mathrm{SpO}_{2}(\%)$ & 98 & 96 & 98 & 98 & 98 & 98 \\
\hline Therapy & $\begin{array}{l}\text { NRM } 8 \\
\text { L/min }\end{array}$ & $\begin{array}{l}\text { NRM } 8 \\
\mathrm{~L} / \mathrm{min}\end{array}$ & $\begin{array}{l}\text { NRM } 6 \\
\text { L/min }\end{array}$ & $\begin{array}{l}\text { NRM } 6 \\
\text { L/min }\end{array}$ & $\mathrm{NC} 5 \mathrm{~L} / \mathrm{min}$ & $\mathrm{NC} 4 \mathrm{~L} / \mathrm{min}$ \\
\hline
\end{tabular}
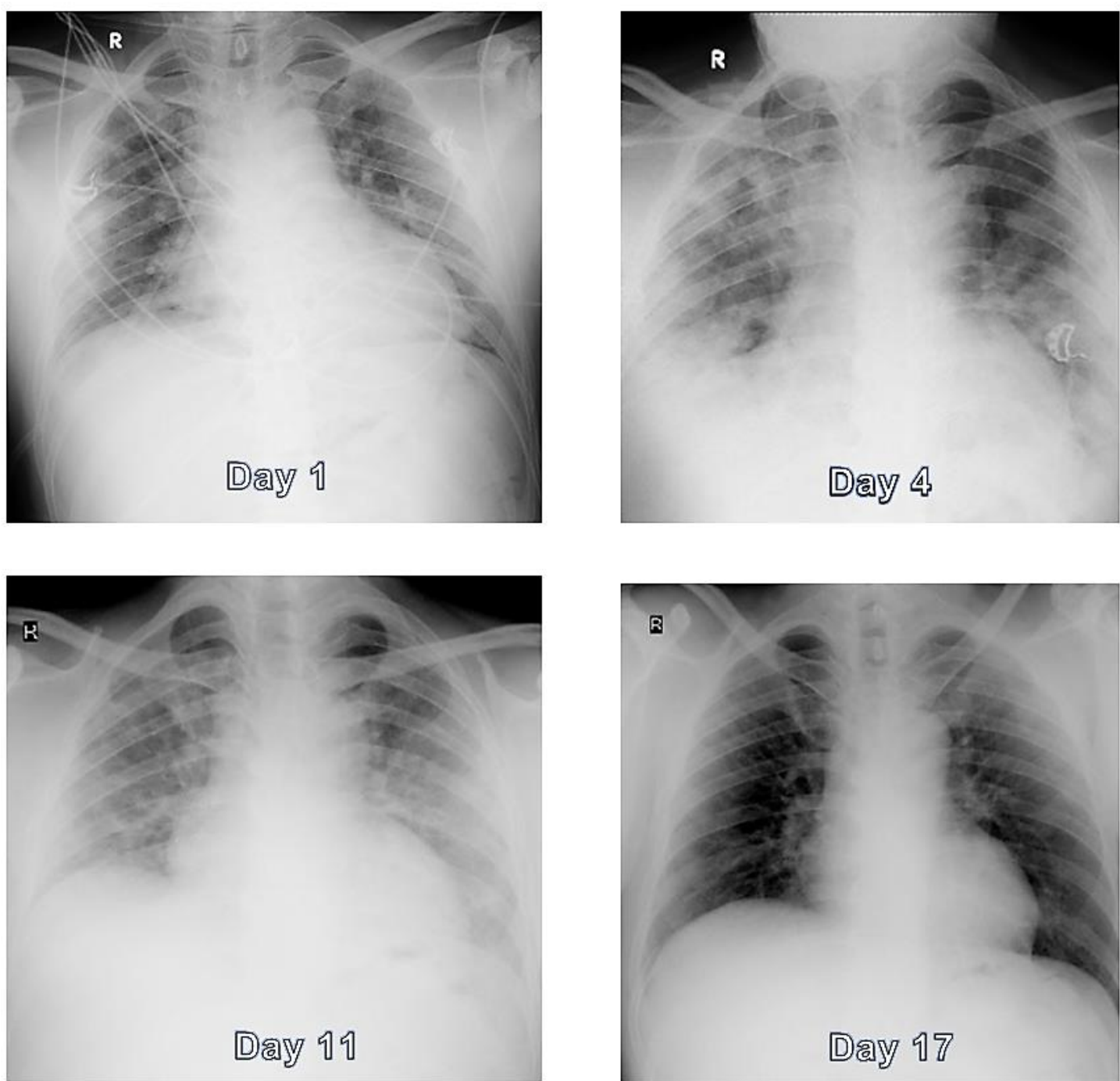

Figure 2: Chest $X$-ray presentations show bilateral infiltrates with ground glass opacity becoming coarser on 1st until 11th day, and the infiltrates reduced on the day 17. 
Table 3: Clinical presentations of the 3rd patient

\begin{tabular}{lllllll} 
Day & $\mathbf{1}$ & $\mathbf{2}$ & $\mathbf{3}$ & $\mathbf{4}$ & $\mathbf{6}$ & $\mathbf{1 1}$ \\
$\mathrm{GCS}$ & Fully alert & Fully alert & Fully alert & Fully alert & Fully alert & Fully alert \\
\hline $\mathrm{BP}(\mathrm{mmHg})$ & $139 / 64$ & $124 / 82$ & $110 / 96$ & $129 / 97$ & $155 / 109$ & $141 / 105$ \\
\hline $\mathrm{HR}(\mathrm{bpm})$ & 129 & 118 & 77 & 89 & 93 & 89 \\
\hline $\mathrm{RR}(\mathrm{xpm})$ & 28 & 28 & 22 & 27 & 27 & 26 \\
\hline Temp $\left({ }^{\circ} \mathrm{C}\right)$ & 39,4 & 38,8 & 36,8 & 36,8 & 36,8 & 36,5 \\
\hline SpO2 $(\%)$ & 96 & 92 & 100 & 95 & 95 & 99 \\
\hline Therapy & $\mathrm{NRM} 8$ & $\mathrm{NRM} 12$ & Helmet & $\mathrm{NRM} 7$ & $\mathrm{NRM} \mathrm{7}$ & $\mathrm{NRM} \mathrm{7}$ \\
& L/min & L/min & CPAP & L/min & L/min & L/min \\
\hline
\end{tabular}

GCS: Glasgow Coma Scale; BP: blood pressure; HR: heart rate; RR: respiratory rate; Temp: temperature; NRM: non rebreathing mask; NC: nasal cannula.
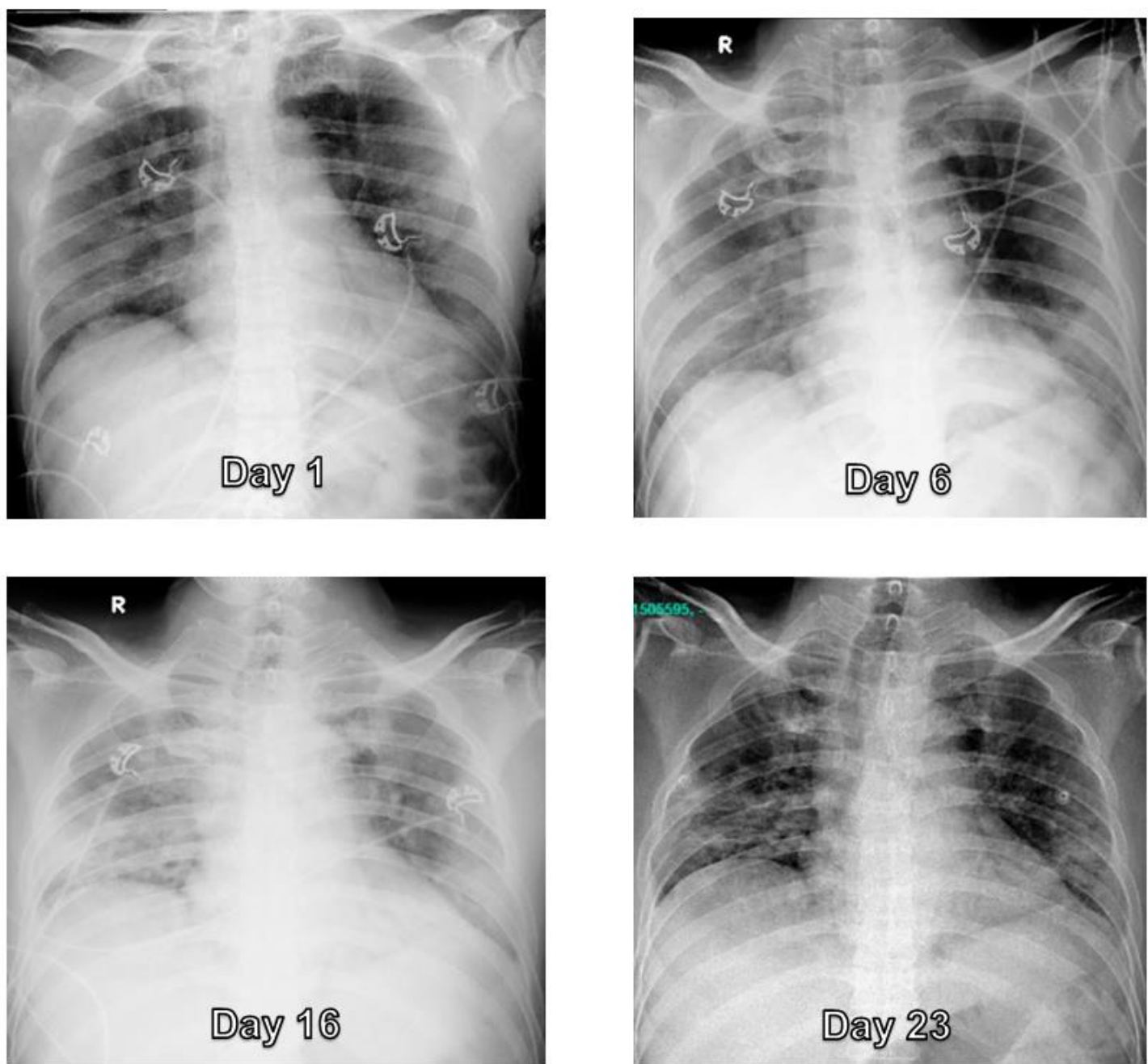

Figure 3: Chest $X$-rays showing bilateral infiltrates, with ground glass opacity becoming coarser from 1st day to 11th day especially in the right hemithorax. 16th to 23rd day, the CXR showed improvement of infiltrates on both lungs 
It can be noted that his oxygen support demand increased from Day 1 until 4, and decreased after Day 4. The $\mathrm{SpO}_{2}$ increased and the oxygen support demand decreased on Day 5 despite the chest X-ray presentation on Day 7 was still showed a worsening condition. On Day 10, patient's clinical condition and CXR were improved, and he was shifter to nasal cannula for oxygen. A negative RT-PCR result on Day 11 was received and the patient was discharged home on Day 13.

\section{Case Report 2}

A male patient, aged $39 \mathrm{y}$, was admitted with confirmed COVID-19 infection. He had a history of fever and cough with blood-stained sputum for a week. He had uncontrolled diabetes mellitus and worked as a medical staff in a hospital that provides care for COVID-19 patients in Central Java. His clinical presentations from Day 1 to Day 11 are presented in Table 2. He was managed by $6-8 \mathrm{~L} / \mathrm{min}$ of oxygen through non rebreathing mask for five days, and then shifted to 4-5 $\mathrm{L} / \mathrm{min}$ oxygen with nasal cannula.

The patient showed marked improving in oxygen demand and the $\mathrm{SpO}_{2}$ on Day 4 despite the worsening chest X-ray results from Day 1 until Day 11 . On Day 5 the X-ray results were worse than Day 4 despite the trend of $\mathrm{SpO}_{2}$ and oxygen demand was getting better. This patient was discharged from hospital on Day 17 with negative PCR result.

\section{Case Report 3}

A 52 y male with confirmed COVID-19 infection, presented with fever, dyspnea, and tachycardia, with no past history of dyspnea or fever. He had diabetes mellitus and hypertension, and worked in an endemic area for COVID-19 infection.

Our 3rd patient showed an increasing oxygen demand from Day 1 until Day 3. He was initially put on 8-12 L/min oxygen through NRM, but on the 3rd day, had to be shifted on helmet CPAP. He started improving from Day 6 onwards, until his discharge from ICU. The $\mathrm{SpO}_{2}$ also improved, despite the CXR showing increased infiltrates on Day 11. After the repeated RT-PCR and the CXR, both showed negative results, the patient was discharged from the hospital on Day 25.

Discussion

CXR is a common tool to diagnose and evaluate the therapy for COVID-19 patients. However, there might be an incoherency between clinical conditions and CXR results in at least some of the patients. The lung CT scan, which has more sensitivity than CXR, was used to learn how this incoherence phenomenon does happen. The research done by Pan and colleagues in 2020 showed that COVID lung CT scan results can be divided into 4 stages. The peak stage is the stage 3 , and the resolution stage is the stage 4 . From study done by them, stage 3 happens on Day $9-13$, and stage 4 happens on Day 14 until the PCR test result is negative. The incoherency between the CXR result and the clinical presentation of our patients might be due to taking the first CXR while the patients were in early stage 3 and the following CXR when the patients were in their early stage 4 , when the peak stage had passed into the resolution phase. Another cause of the incoherency was the lack of sensitivity of CXR compared to lung CT scan, which could result in a false positive result. It looks that to guide the therapy that the clinicians have to rely more on the clinical presentation rather than CXR results due to the possibility of an incoherency between those two. We can use another parameter such as pulse oximetry or blood gas analysis as additional monitoring to evaluate the effectiveness of therapy in COVID-19 infection. ${ }^{9-10}$

\section{Conclusion}

In COVID-19 patients, the clinicians must not depend upon chest X-rays alone for the evaluation of the progress of the treatment and as a guide for the management, as incoherence between CXR and the clinical condition can occur in these patients. The patients; general physical condition and the relevant laboratory test results must also be taking into consideration.

\section{Competing interests}

None declared by the authors. No funding was involved in the management and the manuscript preparation other than the institutional resources.

\section{Authors' contribution}

All authors took part in the management of the cases and the preparation of this manuscript.

\section{References}

1. World Health Organization. Coronavirus Disease (COVID-19) Dashboard 2020. Available from: https://covid19. who.int

2. Covid-19 sp. Data Sebaran Indonesia 2020. Available from: https://covid19.go.id

3. Cohen JP, Dao L, Roth K, Morrison P, Bengio Y, Abbasi AF, et al. Predicting covid-19 pneumonia severity on chest $\mathrm{X}$-ray with deep learning. Cureus. 2020 Jul 28;12(7):e9448. [PubMed] DOI: 10.7759 /cureus.9448

4. Borghesi A, Zigliani A, Golemi S, Carapella N, Maculotti P, Farina $D$, et al. Chest $X$-ray severity index as a predictor of inhospital mortality in coronavirus disease 2019: A study of 302 patients from Italy. Int J Infect Dis. 2020 Jul;96:291-293. [PubMed] DOI: 10.1016/j.jijid.2020.05.021

5. Cleverley J, Piper J, Jones MM. The role of chest radiography in confirming covid-19 pneumonia. BMJ. 2020 Jul 16;370:m2426. [PubMed] DOI: 10.1136/bmj.m2426 
6. Cozzi D, Albanesi M, Cavigli E, Moroni C, Bindi A, Luvarà S, et al. Chest X-ray in new Coronavirus Disease 2019 (COVID-19) infection: findings and correlation with clinical outcome. Radiol Med. 2020 Aug;125(8):730-737. [PubMed] DOI: 10.1007/s11547-020-01232-9

7. Abdelnour LH, Abdalla ME. Progression of CXR features on a COVID-19 survivor. IDCases. 2020;21:e00834. [PubMed] DOI: 10.1016/j.idcr.2020.e00834

8. Wong HYF, Lam HYS, Fong AH, Leung ST, Chin TW, Lo CSY, et al. Frequency and distribution of chest radiographic findings in patients positive for covid-19. Radiology. 2020;296(2):E72E8. [PubMed] DOI: 10.1148/radiol.2020201160

9. Fang $Y$, Zhang $H$, Xie J, Lin M, Ying L, Pang $P$, et al. Sensitivity of chest CT for covid-19: comparison to RT-PCR. Radiology. 2020 Aug;296(2):E115-E117. [PubMed] DOl: 10.1148/radiol.2020200432

10. Pan F, Ye T, Sun P, Gui S, Liang B, Li L, et al. Time course of lung changes at chest ct during recovery from coronavirus disease 2019 (covid-19). Radiology. 2020 Jun;295(3):715-721. [PubMed] DOI: 10.1148/radiol.2020200370 